Boise State University

ScholarWorks

$5-2019$

\title{
The Effect of an Auditor Identity Disclosure Requirement on Audit Quality: An Experimental Examination Incorporating the Incremental Effect of a Signature Requirement
}

\author{
Allen D. Blay \\ Florida State University \\ Eric S. Gooden \\ Boise State University \\ Mark J. Mellon \\ University of South Florida \\ Douglas E. Stevens \\ Georgia State University
}




\title{
The Effect of an Auditor Identity Disclosure Requirement on Audit Quality: An Experimental Examination Incorporating the Incremental Effect of a Signature Requirement*
}

\author{
Allen D. Blay* \\ College of Business \\ Florida State University \\ Tallahassee, FL \\ ablay@fsu.edu \\ Eric S. Gooden \\ College of Business and Economics \\ Boise State University \\ Boise, ID
}

\author{
Mark J. Mellon \\ College of Business \\ Northern Illinois University \\ DeKalb, IL \\ Douglas E. Stevens \\ Robinson College of Business \\ Georgia State University \\ Atlanta, GA
}

* Corresponding author, Allen D. Blay, Department of Accounting, College of Business, Florida State University, Tallahassee, FL 32306-1110. Tel.: +1 850-644-9847. E-mail addresses: ablay@fsu.edu (Allen Blay), ericgooden@boisestate.edu (Eric Gooden), mmellon@niu.edu (Mark Mellon), dstevens11@gsu.edu (Douglas Stevens). This paper has benefitted from the helpful comments of Alisa Brink, Ryan Baxter, Melissa Carlisle, and Mark Cowan. The paper has also incorporated constructive insights from workshop participants at Boise State University, Virginia Commonwealth University (VCU), the American Accounting Association Annual Meeting, the Northwest Accounting Research Group Conference, and the Accounting Behavior and Organizations Conference. The authors would like to thank Jeff Schatzberg and Brian Shapiro for sharing the experimental instructions in Schatzberg, Sevcik, Shapiro, Thorne, and Wallace (2005). Finally, we thank the editor and two anonymous reviewers for their exceptionally helpful comments. The experimental audit markets reported here were conducted at the experimental lab at Florida State University and funded by a research grant from the VCU Department of Accounting.

\begin{abstract}
After considering a proposal to require the engagement partner's signature on the audit report (PCAOB 2009), the Public Company Accounting Oversight Board chose instead to only require the disclosure of the engagement partner's name (PCAOB 2015). This choice was made, however, with little supporting theory or empirical evidence. We make predictions regarding the behavioral effects of the two proposed requirements using insights from social norm activation theory, and test those predictions using an experimental audit market setting found in the literature. We find that both requirements reduce misreporting in the audit report compared to a control setting with neither requirement present. Using a multivariate regression analysis, we also document that the signature requirement generates an incremental reduction in misreporting when added to the disclosure requirement. Finally, we provide evidence that the effects we document are driven by participants with higher sensitivity to social norms as measured by a pre-experiment personality questionnaire. This evidence supports our social norm theory and suggests that policymakers should consider such theory in future policy deliberations. This evidence also supports the new identity disclosure requirement at the PCAOB and helps explain the existence of signature requirements in many non-U.S. countries.
\end{abstract}

Keywords: audit quality; auditor identity disclosure; auditor signature, social norm activation

Data Availability: Experimental data is available from the authors upon request. 
This is an author-produced, peer-reviewed version of this article. The final, definitive version of this document can be found online at Journal of Business Ethics, published by Springer Nature. Copyright restrictions may apply. doi: 10.1007/s10551-017-3561-z

\section{Introduction}

In 2008, the U.S. Department of the Treasury Advisory Committee recommended (Recommendation 6) that the Public Company Accounting Oversight Board (PCAOB) undertake a standard-setting initiative to consider requiring the engagement partner's signature on the audit report (U.S. Department of the Treasury 2008). A similar signature requirement exists in many non-U.S. countries (Chen, Lin, and Lin 2007; Fargher, Lee, and Mande 2008; Carcello and Li 2013). The PCAOB promptly undertook this standard-setting initiative (PCAOB 2008, PCAOB 2009), arguing that a signature requirement would improve the transparency of the audit process and increase the engagement partner's sense of accountability. In solicited comments, auditors generally opposed the signature requirement (Deloitte 2008; Ernst \& Young 2009; PricewaterhouseCoopers 2009), investors and investor groups favored it, and preparers (management and board members) were divided (Carcello and Santore 2015). The Auditing Standards Committee of the Auditing Section of the American Accounting Association also advised caution due to scarce research and inconclusive evidence (King, Davis, and Mintchik 2012). In the face of this opposition, the PCAOB chose instead to only require the disclosure of the engagement partner's name on the audit report (PCAOB 2015).

The purpose of this study is to provide theory and empirical evidence regarding the effectiveness of the two proposed requirements recently considered by the PCAOB. We make predictions regarding the behavioral effects of the two requirements using insights from social norm activation theory (Bicchieri 2006), and test our predictions using an experimental audit market setting based on Magee and Tseng's (1990) economic model of audit pricing and independence. In the model, an auditor is hired by a client to report the value of an asset, and investors purchase the asset from the client at whatever value the auditor reports. In experimental research based on the model, strategic behavior arises whereby auditors receive premium audit fees from clients in exchange for misreporting a low value asset as high value. This strategic behavior transfers wealth from investors to the client and the auditor, and represents a loss of auditor independence. Given the incentive to violate independence, researchers have used this audit market setting to examine the effects of financial incentives, moral reasoning, and social norms on audit quality (Calegari, Schatzberg, and Sevcik 1998; Schatzberg, Sevcik, Shapiro, Thorne, and Wallace 2005; Blay, Gooden, Mellon, and Stevens 2018b). We manipulate whether the auditor's name is publicly disclosed to investor participants and whether auditors also sign off on the audit report by typing their name. ${ }^{1}$ This allows us to examine the effect of an identity disclosure requirement on audit quality as well as the incremental effect of a signature requirement.

Experimental researchers have recently studied the effect of sign-off requirements on opportunistic behavior. For example, Davidson and Stevens (2013) find evidence that signing off on a code of ethics reduces manager opportunism by "activating" (increasing the salience of) social norms found in the code. Similarly, Blay et al. (2018b) find evidence that requiring the auditor to sign off on the audit report increases audit quality by activating social norms for honesty and responsibility. Neither study, however, discloses the names of the manager or the auditor to investors. To date, the only published experimental study that we are aware of that directly tests the two proposed requirements considered by the PCAOB has found evidence that neither one would increase audit quality. ${ }^{2}$ In particular, Cianci, Houston, Montague, and Vogel (2017) find that audit partners make less conservative write-down recommendations when they are told to assume that the PCAOB has issued a new standard requiring their name to be disclosed or requiring their signature on the audit report. However, the authors used a mailed experimental survey with audit partners who, as a group, generally opposed the two regulatory options. This may explain their finding that the two requirements yielded more aggressive writedown judgments by negatively impacting the partners' commitment to the profession and the public.

The PCAOB initially argued that a signature requirement would improve audit quality because "a person exhibits a different behavior when they sign their name to something” (PCAOB 2008). This argument implies a behavioral effect of a signature requirement, but provides little guidance as to the theory behind this effect. Similar to Blay et al. (2018b), we argue that audit quality can be improved to the extent that social norms for honesty and responsibility are activated

\footnotetext{
${ }^{1}$ We chose to have participants type rather than manually sign their name for practical as well as theoretical reasons. First, this allowed us to maintain strong controls consistent with prior experimental audit markets with sign-off requirements (Blay et al. 2018b). Second, in practice auditors commonly provide a digital copy of their signature when a signature requirement is present. Nevertheless, experimental evidence suggests that manually signing one's name rather than printing it can have an incremental behavioral effect associated with one's identity (Kettle and Haubl 2011). This suggests that having participants type their name was a conservative signature manipulation.

${ }^{2}$ In a related experimental study, Lambert, Luippold, and Stefaniak (2018) find evidence that audit partner disclosure on the audit report increases accounting information contagion. In particular, they find evidence that prospective investors are less likely to invest in a peer firm linked to a restating firm via audit partner disclosure, in comparison with a restating firm linked only by industry and auditor. They also find evidence that knowledge of the partner's name increases the extent to which investors attribute blame to the partner for a restatement.
} 
This is an author-produced, peer-reviewed version of this article. The final, definitive version of this document can be found online at Journal of Business Ethics, published by Springer Nature. Copyright restrictions may apply. doi: 10.1007/s10551-017-3561-z

in the auditor. We base our behavioral effects, therefore, on the ability of both the identity disclosure requirement and the signature requirement to activate these social norms in the auditor. Similar to the way these two requirements have been implemented in practice, our research design avoids external accountability effects caused by increased auditor liability. Thus, we examine internal and external accountability effects caused by one's identity and the perceived behavioral expectations of others. ${ }^{3}$ We find that both proposed requirements reduce the amount of misreporting in the audit report compared to a control setting with neither requirement present. In a multivariate regression analysis, we also document that the signature requirement generates an incremental reduction in misreporting when added to the disclosure requirement.

Our experimental study contributes theory and empirical evidence that should be useful to both researchers and policymakers. Audit quality is a multifaceted and ill-defined construct that is difficult to measure using audit engagements in practice due to confounds and simultaneous effects (King et al. 2012). In addition, it is difficult to capture the theoretical effects of a given regulatory policy because only one regulation regime is observed in a given jurisdiction and/or the regulation has been present for many years. ${ }^{4}$ This may explain why researchers have found mixed results using archival methods. An archival study of UK firms by Carcello and Li (2013), for example, found that an audit partner signature requirement improved audit quality whereas a study of firms in the UK and the Netherlands by Blay, Notbohm, Schelleman, and Valencia (2014) found no effect. We provide a powerful test of theory by directly manipulating the two requirements considered by the PCAOB using an experimental audit market found in the literature, and observing their effects on an important aspect of audit quality: auditor independence.

Our study also advances the auditing literature by demonstrating the usefulness of social norm theory in examining auditing regulations and public policy. Researchers in financial and managerial accounting have incorporated social norm theory into the theory of the firm, and have found it useful to examine public policy proposals (Davidson and Stevens 2013) and explain prior anomalous results in the experimental literature (Douthit and Stevens 2014, AbdelRahim and Stevens 2018). ${ }^{5}$ This research follows the advice of Brown, Evans, and Moser (2009) in using the stark predictions of neoclassical economic theory to provide strong tests of alternative behavioral theories. Researchers in auditing, however, have only recently begun to incorporate insights from social norm theory into economic models of audit pricing and independence. For example, Blay et al. (2018b) use an experimental audit market similar to ours to demonstrate that making third-party investors salient and requiring an auditor sign-off without disclosure can improve audit quality by activating social norms in the auditor. Similar to their experimental study, we provide evidence that the effects we document are driven by participants with higher sensitivity to social norms as measured by a preexperiment personality questionnaire, the Jackson Personality Inventory-Revised, (JPI-R hereafter), (Jackson 1994).

The remainder of this paper proceeds as follows. In the following section we present a review of relevant theory and evidence in the literature and develop the hypotheses we test. In the third section we describe the experimental method we use to test our hypotheses. In the fourth section we present the results of our experimental study, and in section five we conclude.

\section{Theory and Hypothesis Development}

The PCAOB based its initial arguments for the audit partner signature requirement (PCAOB 2009) and the eventually chosen identity disclosure requirement (2015) on the potential for such requirements to increase audit quality by increasing transparency and accountability in the audit. The traditional definition of accountability in social psychology is "the implicit or explicit expectation that one may be called on to justify one's beliefs, feelings, and actions to others" (Lerner and Tetlock 1999, 255). Accountability research suggests that people seek approval from the audience to which they are accountable by adopting the known views of that audience (Buchanan, Tetlock, and Reed 1996; Tan, Jubb, and Houghton 1997; Wilks 2002). This suggests a behavioral effect of the two requirements on audit quality based on potential justification to investors (Hoffman and Patton 1997). However, it is unlikely that

\footnotetext{
${ }^{3}$ As we discuss further below, external accountability effects caused by increased auditor liability would likely strengthen our behavioral theoretical link between the proposed regulations and audit quality.

${ }^{4}$ Many countries, such as Australia and Taiwan, have long histories of requiring auditor signatures making it difficult to study the effects of such a requirement (Carey and Simnett 2006; Chi and Chin 2011). The new disclosure requirement in the U.S. became effective for audits on or after December 15, 2017. Thus, it will soon be possible for researchers to use archival data to examine the effect of the new identity disclosure requirement on audit quality. Nevertheless, due to the inherent measurement and control issues related with archival studies, researchers and policymakers would benefit from theory and empirical evidence developed in highly controlled experimental settings such as ours.
}

${ }^{5}$ For a thorough review of the growing body of research incorporating social norms into the theory of the firm, see Stevens (2019). 
This is an author-produced, peer-reviewed version of this article. The final, definitive version of this document can be found online at Journal of Business Ethics, published by Springer Nature. Copyright restrictions may apply. doi: 10.1007/s10551-017-3561-z

engagement partners would expect to justify their actions to investors in practice (Carcello and Li 2013). Further, the proposed regulations were fashioned to hold constant the liability exposure of individual audit partners (Carcello and Li 2013). Therefore, it is unlikely that external accountability effects driven by increased auditor liability would play a significant role in the theoretical effects of the proposed regulations.

We develop a behavioral relation between the proposed regulations and audit quality based on social norm activation theory, which relies on internal and external accountability caused by one's identity and the perceived expectations of others. According to Bicchieri's (2006) model, a social norm is activated when individuals become aware that a behavioral rule is relevant to the current social setting, called the contingency condition, and a combination of empirical and normative expectations give individuals sufficient reason to follow the behavioral rule. Empirical expectations are based on the belief that a sufficiently large subset of people conform to the behavior rule in similar settings, and normative expectations are based on the belief that a sufficiently large subset of people expect conformance to the behavioral rule in similar settings. The choice to follow a social norm, therefore, is conditional upon one's beliefs about the relevance of the norm to the current social setting (contingency condition), how many other people follow the norm in similar settings (empirical expectations), and whether one is expected to follow the norm in turn (normative expectations). ${ }^{6}$

Social norm activation is conditional on one's self-image or self-concept (Bicchieri 2006, 85-86). One of the most prominent of the social norms found in society is honesty (Murphy 1993). Thus, people like to think of themselves as honest (Mazar, Amir, and Ariely 2008). Further, people like to think of themselves as responsible when they are asked to represent the interests of others. Given that misreporting on the audit report is misleading and potentially costly to third party investors, auditors are likely to identify honesty and responsibility as behavioral rules that would apply in an audit market setting (Blay et al. 2018b). This suggests that Bicchieri's (2006) contingency condition is met for honesty and responsibility norms in audit market settings. This also suggests that audit regulations can increase audit quality by increasing the belief that other auditors conform to honesty and responsibility norms in audit settings (empirical expectations) or increasing the belief that auditors in general are expected to conform to these norms in the audit (normative expectations).

Bicchieri's model provides three motivations for an auditor to comply with an honesty or responsibility norm that has been activated in an audit market setting: 1) fear of the consequences, 2) the desire to please, and 3) acceptance of the social norms as valid (Bicchieri 2006, 23-24). The first motivation may exist because the auditor fears negative sanctions from violating an honesty or responsibility norm in the audit, such as when auditor liability exists. Bicchieri's model extends traditional economic theory by including negative behavioral sanctions such as resentment that could exist in the absence of auditor liability. The second motivation may exist because the auditor desires to please others by fulfilling their normative expectations for honesty and responsibility in the audit. Again, Bicchieri's model extends traditional economic theory by including positive behavioral rewards such as dignity and respect. The first two motivations relate to external accountability and may have economic implications for the auditor, at least in the long run. The third motivation has no equivalent in traditional economic theory in that it relates to internal accountability and provides a reason for the auditor to behave consistent with an honesty or responsibility norm even when that behavior is private and will not be directly observed by others.

This discussion provides a behavioral relation between the two proposed regulations and audit quality that is independent of external accountability caused by increased auditor liability. Nevertheless, social norm activation theory also suggests that increasing auditor liability would strengthen this behavioral effect by increasing the consequences to violating these social norms. The theory also suggests that auditors will be differentially affected by the proposed regulations due to diffences in social norm sensitivity. For example, normative expectations for an honesty or responsibility norm may be satisfied in some auditors by the mere belief that there are valid reasons for

\footnotetext{
${ }^{6}$ Bicchieri $(2006,59)$ defines social norm activation as follows: “To 'activate' a norm means that the subjects involved recognize that the norm applies: They infer from some situational cues what the appropriate behavior is, what they should expect others to do, and what they are expected to do themselves, and act upon those cues. It is the cues one focuses on that govern the mapping from context to interpretation and, ultimately, the activation of social norms.” Bicchieri’s (2006) formal model is presented in its entirety in Davidson and Stevens (2013). For a detailed discussion of Bicchieri’s model and its usefulness to experimental research, see Blay, Gooden, Mellon, and Stevens (2018a), and Stevens (2019).
} 
This is an author-produced, peer-reviewed version of this article. The final, definitive version of this document can be found online at Journal of Business Ethics, published by Springer Nature. Copyright restrictions may apply. doi: 10.1007/s10551-017-3561-z

following such norms, whereas other auditors may require the belief that violations of such norms will be detected and sanctioned. The former condition would be true of an auditor who has high social norm sensitivity whereas the latter would be true of an auditor who has low social norm sensitivity. ${ }^{7}$

Given the above intuition, we expect both an auditor identity disclosure requirement and a signature requirement to activate social norms for honesty and responsibility in the auditor. Based on social norm activation theory (Bicchieri 2006) and supporting experimental evidence in Blay et al. (2018b), we expect the activation of these two social norms to reduce misreporting in the audit report. Thus, we predict that an auditor identity disclosure requirement will reduce misreporting in the audit report. We also predict that a signature requirement, which also includes identity disclosure, will reduce misreporting in the audit report. We test these predictions formally in our first two hypotheses:

\section{H1: (Identity Disclosure Requirement) Requiring the auditor's identity to be disclosed to investors will reduce misreporting in the audit report.}

\section{H2: (Signature Requirement) Requiring the auditor to sign off on the audit report will reduce misreporting in the audit report.}

By examining both the identity disclosure requirement and the signature requirement considered by the PCAOB, we are also able to examine the incremental effect of a signature requirement on audit quality over an identity disclosure requirement alone. Given results in prior experimental studies of the effects of signing off on a code of ethics or an audit report without identity disclosure (Davidson and Stevens 2013; Blay et al. 2018b), we expect that adding a signature requirement to an identity disclosure requirement will further activate social norms for honesty and responsibility in the auditor. In particular, adding a signature requirement is likely to generate additional internal and external accountability caused by one's identity as honest and responsible and the perceived behavioral expectations of others that the auditor exhibit such social norms in the audit. Thus, we predict an incremental effect of a signature requirement whereby adding a signature requirement to an identity disclosure requirement will further reduce misreporting in the audit report. We test this prediction formally in our third hypothesis:

\section{H3: (Incremental Effect of a Signature Requirement) Adding a signature requirement to an identity disclosure requirement will further reduce misreporting in the audit report.}

\section{Experimental Method}

\section{$\underline{\text { Experimental Audit Market }}$}

To test our three hypotheses, we used an experimental audit market setting found in the literature (Calegari et al. 1998; Schatzberg et al. 2005; Blay et al. 2018b). Each audit market consisted of four auditors designated by number (one, two, three, and four), four clients designated by color (green, orange, yellow, and pink), and two investors designated by number (one and two). The auditor, client, and investor roles were randomly assigned and fixed throughout each experimental session. ${ }^{8}$ Each audit market operated for ten trading years and each trading year consisted of two trading periods. ${ }^{9}$ In order to mitigate end of period effects, participants were not informed as to how long the market would be in operation. To maintain independence between trading years, participants were also randomly reassigned to new market groups at the end of each trading year. All manipulations were on a between-subjects basis. The experimental audit markets were programmed and conducted using Z-tree software (Fischbacher 2007).

\footnotetext{
${ }^{7}$ Although Bicchieri assumes that sensitivity to a given social norm varies across individuals and particular norms, she takes an individual's sensitivity to a particular norm to be a fairly stable disposition (Bicchieri 2006, 116). Nevertheless, her model suggests that even auditors with low social norm sensitivity can be motivated to follow an honesty or responsibility norm given sufficient situational cues that activate such norms. Further, her model suggests that auditors with high social norm sensitivity may not be motivated to follow these norms if such situational cues are absent.

${ }^{8}$ As with prior experimental audit markets, these three roles were labelled using neutral terminology (i.e., seller, verifier, and buyer) to guard against the extraneous influence of role playing. For clarity and simplification, however, we use the role labels found in practice throughout the rest of the paper.

${ }^{9}$ The inclusion of two trading periods per trading year is consistent with the economic model in Magee and Tseng (1990), which incorporated the motivation for low-ball pricing in period one due to quasi-rents in period two. Similar to prior experimental studies based on their model, the inclusion of a second period motivated auditors to violate their independence in period one by accepting premium audit fees in return for misreporting at the expense of investors.
} 
This is an author-produced, peer-reviewed version of this article. The final, definitive version of this document can be found online at Journal of Business Ethics, published by Springer Nature. Copyright restrictions may apply. doi: 10.1007/s10551-017-3561-z

At the start of each trading period, each of the four clients was given an asset whose value was unknown. Before they could sell their asset to investors, the clients were required to hire an auditor to verify and report the asset's value. Each of the four auditors then submitted a separate price offer, via a sealed-offer auction, to each of the four clients to perform this audit service. That is, each auditor competed on price to perform an audit service for each client in the market. As with prior experimental studies using this audit market setting, however, offering a premium audit fee became a signal to clients that the auditor was willing to misreport and incur the penalty for misreporting. Next, each client received the price offers from each auditor, selected one auditor, and paid the selected auditor their price offer. Auditors then observed the value of the asset, which had a 100 percent probability of being low (\$2.68). However, auditors could publicly report that the asset’s value was either low (\$2.68) or high (\$3.68). The significance of the auditor's report is that the reported value determined the price the investors paid the clients for their assets. ${ }^{10}$ Each investor purchased an asset from two distinct clients. Investor 1 purchased the assets of the green and orange clients and Investor 2 purchased the assets of the yellow and pink clients.

The earnings of participants in a given experimental session were determined as follows. All participants received a show-up fee of $\$ 10$ in addition to their earnings during the experiment. Auditors and clients began the experiment with an initial endowment of $\$ 10.00$ and investors began the experiment with an initial endowment of $\$ 20.00$. The auditor's per period earnings consisted of the fees from each client with whom (s)he contracted with, less a fixed observation cost of $\$ 1.60$ per contract, less a $\$ 0.40$ learning cost per service in the initial audit period that was waived in period two if the incumbent auditor was rehired by the client. Consistent with prior experiments using this market setting (Schatzberg et al. 2005; Blay et al. 2018b), auditors also received $\$ 0.20$ per period to minimize payout differences between experimental roles. Lastly, the auditor was assessed a $\$ 0.05$ misreporting penalty when (s)he misreported the value of the asset. ${ }^{11}$

The client's per period earnings consisted of the auditor's reported value of the asset (\$2.68 or \$3.68), less the auditor's fee, less a $\$ 0.30$ hiring fee that was waived in period two if the incumbent auditor was rehired by the client. The investor's per period earnings were zero when the auditor truthfully reported the value of the asset as low and negative one dollar (-\$1.00) when the auditor misreported the value of the asset as high. Participants were paid in private based on their \$10 show-up fee, their initial endowment, and their cumulative earnings from the trading periods after completing the post-experimental questionnaire. Prior to the experimental rounds, participants were required to correctly respond to seven multiple choice questions about the operation of the audit market. Table 1 presents the experimental payouts by participant-type. Given our experimental parameters and procedures, average payouts were \$25.83, \$35.65, and \$20.17 for auditors, clients, and investors respectively.

[Insert Table 1 about here]

\section{Competitive-Equilibrium Reporting Prediction}

As elaborated upon by Schatzberg et al. (2005, p. 241), the non-cooperative, competitive-equilibrium reporting prediction in our experimental audit markets is for auditors to truthfully report in both trading periods. The intuition behind this Nash equilibrium can be arrived at through backward induction. The only motivation for the auditor to misreport and incur the misreporting penalty is the opportunity to accrue future "quasi-rents" from the client. ${ }^{12}$ After contracting with the client at the beginning of period two, however, the auditor has no expectation of obtaining future quasi-rents from the client. Accordingly, no auditor (incumbent or nonincumbent) is expected to misreport in period

\footnotetext{
${ }^{10}$ Each auditor's price offer was restricted to range between $\$ 0.00$ and $\$ 4.00$, but auditors could propose different fees to different clients, and could make price offers below their cost if they so chose. Since each auditor submitted bids to each client, a single auditor could be hired by all four clients in the market.

${ }^{11}$ We use the same experimental parameters as the experimental audit markets in Schatzberg et al (2005), and Blay et al. (2018b) with one notable exception. We held the penalty for misreporting at a relatively low level of $\$ 0.05$ to increase the economic incentive for misreporting in the audit report.

${ }^{12}$ DeAngelo (1981) defines quasi-rents as cost advantages that accrue to the incumbent auditor, which include technological and learning advantages of the incumbent as well as switching costs incurred by the client.
} 
This is an author-produced, peer-reviewed version of this article. The final, definitive version of this document can be found online at Journal of Business Ethics, published by Springer Nature. Copyright restrictions may apply. doi: 10.1007/s10551-017-3561-z

two after contracting with the client. Given the knowledge that the client will not be better off by hiring a nonincumbent auditor in period two (i.e. there is no credible dismissal threat), no auditor will misreport in period one after contracting with the client. ${ }^{13}$

In contrast to this non-cooperative reporting strategy, prior experimental audit markets based on Magee and Tseng's model have yielded a cooperative reporting strategy whereby the auditor quotes a premium audit fee that more than covers the penalty for misreporting as a signal to potential clients that (s)he is willing to misreport the value of the asset as high (Calegari et al., 1998; Schatzberg et al., 2005; Blay et al., 2018b). In period one, an auditor who contracts for a premium audit fee is motivated to misreport in the audit report because the client can penalize an auditor who does not misreport by hiring a different auditor in period two. Given that misreporting transfers $\$ 1.00$ from the investor to the client and auditor, this cooperative behavior yields higher returns to the client and auditor than truthful reporting. This cooperative reporting strategy is not likely to arise in period two, however, because the auditor has a strong incentive to defect and report truthfully after receiving the premium audit fee. Given the lack of incentive to misreport in period two, we focus on misreporting behavior in period one as in Blay et al. (2018b).

\section{Dependent Variable}

Consistent with prior experimental studies based on Magee and Tseng's model (Calegari et al. 1998; Schatzberg et al. 2005; Blay et al. 2018b), the actual value observed by auditors is always low. However, auditors could report the value of the client's asset as either low (\$2.68) or high (\$3.68). Thus, misreporting in the audit report occurred when an auditor reported that the client possessed a high-value asset rather than a low-value asset. Accordingly, the dependent variable we use to capture audit quality is a dichotomous misreporting variable (Misreport).

\section{Manipulated Variables}

Our experimental study incorporates a 3x1 between-participants experimental design. This design includes a control experimental condition with no identity disclosure requirement or signature requirement (No Disclosure or Signature), an experimental condition with an identity disclosure requirement (Disclosure Only), and an experimental condition with a signature requirement that included identity disclosure (Disclosure and Signature). The identity disclosure requirement was operationalized by having the auditor's name revealed to the investor as part of the audit report and the signature requirement was operationalized by having the auditor type their name in addition to having their name revealed to the investor. Panel A of Table 2 presents a summary of our full experimental design.

[Insert Table 2 about here]

\section{Measured Variables}

We measure social norm sensitivity in the auditor using two personality scales from the JPI-R, (Jackson 1994). ${ }^{14}$ The Traditional Values scale assesses the degree to which an individual values traditional norms and beliefs, and is the opposite of moral relativism. Individuals with higher Traditional Values scores, therefore, are likely to be more sensitive to a norm for honest reporting. The Responsibility scale of the JPI-R captures the degree to which an individual feels an abstract moral obligation to other people and to society at large, and is the opposite of negligence. Individuals with higher Responsibility scores, therefore, are likely to be more sensitive to a norm for responsible reporting. Both personality scores were collected as part of a pre-experimental questionnaire by having participants complete 20 true/false questions, resulting in a theoretical range from $0-20$ per personality score. Panel B of Table 2 presents a summary of our two social norm sensitivity measures in period one.

\footnotetext{
${ }^{13}$ Similar to Calegari et al. (1998), Schatzberg et al. (2005), and Blay et al. (2018b), we find that misreporting in period two is much lower than in period one. Magee and Tseng's (1990) model also yields economic predictions regarding auditor fee behavior. Since auditor fees are not examined in this study, however, we omit discussion of these predictions and results.

${ }^{14}$ The JPI-R is a 300-item instrument that measures 15 personality scales that are relevant to the functioning of a person in a wide range of settings including: work, organizational behavior, and interpersonal situations. Experimental researchers have used the JPI-R to examine the effect of social norms on honest reporting in auditing (Blay et al. 2018b) and participative budgeting settings (Stevens 2002; Hobson, Mellon, and Stevens 2011).
} 
This is an author-produced, peer-reviewed version of this article. The final, definitive version of this document can be found online at Journal of Business Ethics, published by Springer Nature. Copyright restrictions may apply. doi: 10.1007/s10551-017-3561-z

\section{Results}

\section{Participants and Manipulation Checks}

The experimental audit markets we report involved 120 undergraduate students from a large southeastern university. As discussed above, participants were randomly assigned roles such that each market was comprised of four auditors, four clients, and two investors. To achieve independent observations, participants were informed that they would be randomly reassigned to a new audit market at the end of each investment year (two periods). This is an experimental design departure from early experimental studies using Magee and Tseng's model (Calegari et al. 1998; Schatzberg et al. 2005), and was chosen in order to reduce the serial correlation in previous studies (Blay et al. 2018b). However, it is possible that our observations are influenced by a simultaneous learning process by individual market participants across the audit markets. As such, due care should be followed when interpreting our statistical tests.

We use responses to items on the exit questionnaire to test the effectiveness of our experimental manipulations. Responses ranged from $1=$ strongly disagree to $7=$ strongly agree $(4=$ neutral $)$. Participants responded to the following question regarding the identity disclosure experimental manipulation: "When reporting the value of the asset the auditor's actual name was disclosed to the investor." ${ }^{15}$ Participants in the two disclosure treatments (Disclosure Only and Disclosure and Signature) responded differently to this statement than participants in the nondisclosure control group $(t=7.950$, d.f. $=118, \mathrm{p}<0.001) .{ }^{16}$ The mean response of $5.06(\mathrm{SD}=2.22)$ for participants in the two disclosure treatments is significantly above the neutral response of $4(\mathrm{t}=4.284$, d.f. $=79, \mathrm{p}<0.01)$ whereas the mean response of $1.85(\mathrm{SD}=1.79)$ for participants in the No Disclosure or Signature control group is significantly below the neutral response of $4(t=7.592$, d.f. $=39, \mathrm{p}<0.01)$. This suggests that our identity disclosure manipulation was successful.

Participants responded to the following question regarding the auditor signature manipulation: "Prior to submitting their audit report, each auditor was required to type their name on their report." Participants in the Disclosure and Signature treatment responded differently to this statement than participants in the No Disclosure or Signature treatment or the Disclosure Only treatment $(\mathrm{t}=8.599$, d.f. $=118, \mathrm{p}<0.001)$. The mean response of $5.18(\mathrm{SD}=2.41)$ for participants in the Disclosure and Signature treatment is significantly above the neutral response of $4(\mathrm{t}=3.089$, d.f. $=39, \mathrm{p}<0.01)$ whereas the mean response of $1.98(\mathrm{SD}=1.63)$ for participants in the other two treatments is significantly below the neutral response of $4(\mathrm{t}=11.110$, d.f. $=79, \mathrm{p}<0.01)$. This suggests that our auditor signature manipulation was successful.

\section{$\underline{\text { Hypothesis Tests }}$}

As discussed above, an incentive for the auditor to violate independence and misreport in the audit report was only present in period one. Consistent with Blay et al. (2018b), therefore, we use misreporting behavior in period one to test our three hypotheses. Table 3 presents the average misreporting in period one across the three experimental conditions and by low and high social norm sensitivity. Consistent with Hypothesis 1, the results for overall misreporting show less misreporting in the Disclosure Only condition (30.3\%) than in the No Disclosure or Signature condition (41.9\%). Consistent with Hypothesis 2, the results for overall misreporting also show less misreporting in the Disclosure and Signature condition (26.1\%) than in the No Disclosure or Signature condition (41.9\%). According to untabled Pearson chi-square tests of significance, these differences are statistically significant at the $5 \%$ level $\left(\chi^{2}(1\right.$, $\mathrm{N}=302)=4.367, \mathrm{p}=0.037)$ and $1 \%$ level $\left(\chi^{2}(1, \mathrm{~N}=294)=7.990, \mathrm{p}=.005\right)$, respectively. The results for overall misreporting, therefore, support the predicted effects of the two regulations recently considered by the PCAOB.

\section{[Insert Table 3 about here]}

Our third hypothesis predicts an incremental effect of the signature requirement over the identity disclosure requirement. While the results for overall misreporting show less misreporting in the Disclosure and Signature condition (26.1\%) than in the Disclosure Only condition (30.3\%), an untabled Pearson chi-square test reveals that this difference is not statistically significant $\left(\chi^{2}(1, N=276)=0.589, p=0.443\right)$. Our social norm theory suggests, however, that our predicted effects will be driven by auditors with higher social norm sensitivity. To explore the effect of social

\footnotetext{
${ }^{15}$ As discussed above, we used the labels "verifier" and "buyer" in place of "auditor" and "investor" in both the instructions and exit questionnaire items.

${ }^{16}$ All of our manipulation check analysis included all participants (120 total), and all participant types (verifiers, buyers, and auditors).
} 
This is an author-produced, peer-reviewed version of this article. The final, definitive version of this document can be found online at Journal of Business Ethics, published by Springer Nature. Copyright restrictions may apply. doi: 10.1007/s10551-017-3561-z

norm sensitivity on our results, we initially perform a median split of participants based on our two measures of social norm sensitivity from the JPI-R and present average misreporting by low and high social norm sensitivity. ${ }^{17}$ While our two measures of social norm sensitivity are highly correlated (Pearson Correlation $=.461, \mathrm{p}=.001$ ), Table 3 reveals that the results are stronger using the Responsibility scale than the Traditional Values scale. The results for auditors who scored high in Traditional Values show less misreporting in the Disclosure and Signature condition (22.0\%) than in the Disclosure Only condition (27.0\%), but an untabled Pearson chi-square test reveals that this difference is not statistically significant $\left(\chi^{2}(1, N=119)=0.273\right.$, one-tailed $\left.\mathrm{p}=0.183\right)$. The results for auditors who scored high in Responsibility, however, reveal that the difference between misreporting in the Disclosure and Signature condition (3.1\%) is highly significantly different from the Disclosure Only condition (17.8\%), $\left(\chi^{2}(1, \mathrm{~N}=154)\right.$ $=3.890$, one-tailed $\mathrm{p}=0.003)$. The weaker results for the Traditional Values scale can be explained by the fact that it captures other values besides honesty (e.g., frugality, modesty, respect for authority, and patriotism). Thus, the Traditional Values scale we used to capture the auditor's sensitivity to an honesty norm is likely a weak measure of our theoretical construct.

To more adequately control for social norm sensitivity and the presence of other variables in the model, we perform multivariate logistic regression analysis to test our three hypotheses. We present four logistic regression models of misreporting in period one in Table 4. In the first two regression models, both Disclosure and Disclosure \& Signature are significant at the 5\% level when alone in the model (Model 1) and with the accepted audit fee in the model (Model 2). The accepted audit fee captures cooperative behavior between the auditor and the client at the expense of investors, and is significantly positive as predicted $(\mathrm{p}<0.05)$ when included in the model. These results provide strong evidence that the identity disclosure requirement and the signature requirement reduce misreporting in the audit report, consistent with Hypotheses 1 and 2. Because this multivariate analysis controls for other variables in the model, the significance of the Disclosure \& Signature variable also provides strong evidence that adding a signature requirement to the identity disclosure requirement further reduces misreporting in the audit report, consistent with Hypothesis 3.

The third regression model (Model 3) shows that Disclosure becomes insignificant and Signature \& Disclosure is only marginally significant $(\mathrm{p}<0.10)$ when the Responsibility and Traditional Values variables are added to the model. Consistent with the univariate results above, Responsibility is highly significant $(\mathrm{p}<0.01)$ while Traditional Values is not significant $(\mathrm{p}>0.10)$ when included in the model. To directly test our underlying social norm theory, the fourth regression model (Model 4) includes a dichotomous variable for High Responsibility auditors and the two interactions of this variable with our two manipulations. This regression model shows the best fit with the data as revealed in both the Chi-square statistic and the Negelkerke $\mathrm{R}^{2}$. The main effect for High Responsibility and the two interaction terms are highly significant $(\mathrm{p}<0.01$ ) when added to the model, revealing that auditors who scored high on this measure of social norm sensitivity exhibited lower misreporting on average and significantly reduced their misreporting in response to the two experimental manipulations. These results provide evidence that the effects we document are driven by participants with higher sensitivity to social norms consistent with our underlying social norm theory.

[Insert Table 4 about here]

\section{Conclusion}

After considering a proposal to require the engagement partner's signature on the audit report (PCAOB 2009), the Public Company Accounting Oversight Board chose instead to only require the disclosure of the engagement partner's name (PCAOB 2015). This choice was made, however, without supporting theory or empirical evidence. The PCAOB based its initial arguments in support of the two requirements on the potential for each one to increase audit quality by increasing transparency and accountability in the audit. Traditional theory in social psychology and economics, however, provides little support for this accountability argument. The accountability literature in social psychology relies on the potential for face-to-face justification (Lerner and Tetlock 1999, 255) and the proposed regulations were fashioned to hold constant the liability exposure of individual audit partners (Carcello and Li 2013). We develop a behavioral relation between the proposed regulations and audit quality based on social norm activation theory, which relies on internal and external accountability caused by one's identity and the perceived expectations of others. Our social norm theory provides theoretical support for the accountability argument put forth by the PCAOB, yet yields new insights regarding the form of that accountability and the potential for the proposed regulations to improve audit quality.

\footnotetext{
${ }^{17}$ We also performed identical analyses using one standard deviation above the mean and obtained inferentially identical results.
} 
This is an author-produced, peer-reviewed version of this article. The final, definitive version of this document can be found online at Journal of Business Ethics, published by Springer Nature. Copyright restrictions may apply. doi: 10.1007/s10551-017-3561-z

We test our behavioral relation between the two proposed requirements and audit quality using an experimental audit market setting found in the literature. We find that both an identity disclosure requirement and a signature requirement reduce misreporting in the audit report compared to a control setting with neither requirement present. Using a multivariate regression analysis, we also document that the signature requirement generates an incremental reduction in misreporting when added to the disclosure requirement. Finally, we provide evidence that the effects we document are driven by participants with higher sensitivity to social norms as measured by a pre-experiment personality questionnaire. This evidence supports our social norm theory and suggests that policymakers should consider such theory in future policy deliberations.

As with prior experimental audit market studies (Calegari et al. 1998; Schatzberg et al. 2005; Blay et al. 2018b), we base our audit market setting on Magee and Tseng's (1990) model of audit pricing and independence. Thus, our experimental setting captures essential features of audit markets in practice. Given this feature of our experimental audit market, we believe that our study provides useful theory and empirical evidence regarding the new identity disclosure requirement at the PCAOB and helps explain the frequent use of auditor signature requirements in many non-U.S. countries. For example, our study supports the usefulness of social norm theory in describing differences in auditing regulations and policy across various countries. In particular, our evidence suggests that non-U.S. countries may have higher levels of social norm sensitivity or may rely on such sensitivity to a greater extent than U.S. policymakers. This opens up a whole new area of research examining cultural differences in social norm sensitivity and potential ways of increasing such sensitivity in auditors. This supports the use of social norm theory as both a positive and normative theory for auditing research.

Our results appear to conflict with a recent experimental study by Cianci et al. (2017), who find that audit partner participants make less conservative write-down recommendations when they are told to assume that the PCAOB has issued a new standard requiring that their name be disclosed or their signature appear on the audit report. Our experimental study differs from theirs in several important aspects. First, our audit market setting contains an economic incentive to misreport in the audit report and the potential for social norm activation to offset this incentive. Second, we use student participants rather than audit partners. Given our desire to provide a strong test of economic and social norm theory, our use of student participants appears appropriate (Libby, Bloomfield, and Nelson 2002). Cianci et al.'s use of audit partners also appears appropriate as it allowed them to test theory suggesting that the regulations would reduce commitment to the profession and the public in audit partners. Thus, our two studies provide different yet complementary perspectives and promote the importance of examining potential regulations with multiple research methods. Nevertheless, further research appears warranted to reconcile our experimental results with theirs.

The results and implications of this study are subject to the normal caveats associated with experimental research. In particular, this study contains a stark audit market setting that abstracts significantly from audit market settings in practice. For example, investors are passive players in our audit market and other elements of external accountability such as litigation risk are intentionally excluded. We consider this to be a strength of our study because it enables us to isolate the behavioral mechanisms raised by the PCAOB in their deliberations of the two proposed regulations, which were specifically designed to control for increased litigation risk (PCAOB 2009, PCAOB 2015). Our theory and experimental evidence suggest that these two regulations could improve audit quality by activating social norms in the auditor. Our theory also suggests that incorporating auditor litigation would strengthen these social norm effects. Another potential extension of this research is to examine how external accountability mechanisms such as investor activism or auditor liability interact with social norm activation to affect audit quality. 
This is an author-produced, peer-reviewed version of this article. The final, definitive version of this document can be found online at Journal of Business Ethics, published by Springer Nature. Copyright restrictions may apply. doi: 10.1007/s10551-017-3561-z

\section{References}

Abdel-Rahim, H., and D. Stevens. 2018. Information system precision and honesty in managerial reporting: A reexamination of information asymmetry effects. Accounting, Organizations and Society 64: 31-43.

Bicchieri, C. 2006. The Grammar of Society: The Nature and Dynamics of Social Norms. Cambridge, UK: Cambridge University Press.

Blay, A., E. Gooden, M. Mellon, and D. Stevens. 2018a. The usefulness of social norm theory in empirical business ethics research: A review and suggestions for future research. Journal of Business Ethics 152(1): 191-206. , E. Gooden, M. Mellon, and D. Stevens. 2018b. Can Social Norm Activation Improve Audit Quality? Evidence from an Experimental Audit Market. Journal of Business Ethics, (in press) doi: 10.1007/s10551017-3561-z

, M. Notbohm, C. Schelleman, and A. Valencia. 2014. Audit quality effects of an individual audit engagement partner signature mandate. International Journal of Auditing 18(3): 172-192.

Brown, J., J. Evans III, and D. Moser. 2009. Agency theory and participative budgeting experiments. Journal of Management Accounting Research 21(1): 317-345.

Buchanan, T., P. Tetlock, and R. Reed. 1996. Accountability and auditors' judgments about contingent events. Journal of Business Finance and Accounting 23(3): 379-398.

Calegari, M., J. Schatzberg, and G. Sevcik. 1998. Experimental evidence of differential audit pricing and reporting strategies. The Accounting Review 73(2): 255-275.

Carcello, J., and C. Li. 2013. Costs and benefits of requiring an engagement partner signature: Recent experience in the United Kingdom. The Accounting Review 88(5): 1511-1546. , and R. Santore. 2015. Engagement partner identification: A theoretical analysis. Accounting Horizons 29(2): 297-311.

Carey, P., and R. Simnett. 2006. Audit partner tenure and audit quality. The Accounting Review 81(3): 653-676.

Chen, C., C. Lin, and Y. Lin. 2007. Audit partner tenure, audit firm tenure, and discretionary accruals: Does long auditor tenure impair earnings quality? Contemporary Accounting Research 25(2): 415-445.

Chi, H., and C. Chin. 2011. Firm versus partner measures of auditor industry expertise and effects on auditor quality. Auditing: A Journal of Practice \& Theory 30(2): 201-229.

Cianci, A., R. Houston, N. Montague, and R. Vogel. 2017. Audit partner identification: Unintended consequences on audit judgment. Auditing: A Journal of Practice and Theory 36(4): 135-149.

Davidson, B., and D. Stevens. 2013. Can a code of ethics improve manager behavior and investor confidence? An experimental study. The Accounting Review 88(1): 51-74.

DeAngelo, L. 1981. Auditor independence, ‘low balling', and disclosure regulation. Journal of Accounting and Economics 3(2): 113-127.

Deloitte, LLP. 2008. Comment Letter to PCAOB Rulemaking Docket Matter No. 29. Available at http://comments.treas.gov/_files/DeloitteLLPCommentLetter.pdf.

Douthit, J., and D. Stevens. 2014. The robustness of honesty effects on budget proposals when the superior has rejection authority. The Accounting Review 90(2): 467-493.

Ernst \& Young LLP. 2009. Comment on PCAOB Concept Release on Requiring the Engagement Partner to Sign the Audit Report. PCAOB Release No. 2009-005 (September 10).

Fargher, N., H. Lee, and V. Mande. 2008. The effect of audit partner tenure on client managers' accounting discretion. Managerial Auditing Journal 23(2): 161-186.

Fischbacher, U. 2007. z-Tree: Zurich toolbox for ready-made economic experiments. Experimental Economics 10(2): 171-178.

Hobson, J., M. Mellon, and D. Stevens. 2011. Determinants of moral judgments regarding budgetary slack: An experimental examination of pay scheme and personal values. Behavioral Research in Accounting 23(1): 87-107.

Hoffman, V., and J. Patton. 1997. Accountability, the dilution effect, and conservatism in auditors' fraud judgments. Journal of Accounting Research 35(2): 227-237.

Jackson, D. 1994. Jackson Personality Inventory-Revised Manual. Sigma Assessment Systems, Inc.: Port Huron, MI.

Kettle, K. and G. Haubl. 2011. The signature effect: Signing influences consumption-related behavior by priming self-identity. Journal of Consumer Research 38(3): 474-489.

King, R., S. Davis, and N. Mintchik. 2012. Mandatory disclosure of the engagement partner's identity: potential benefits and unintended consequences. Accounting Horizons 26(3): 533-561. 
This is an author-produced, peer-reviewed version of this article. The final, definitive version of this document can be found online at Journal of Business Ethics, published by Springer Nature. Copyright restrictions may apply. doi: 10.1007/s10551-017-3561-z

Lambert, T., B. Luippold, and C. Stefaniak. 2018. Audit Partner Disclosure: An Experimental Exploration of Accounting Information Contagion. Behavioral Research in Accounting 30(1): 27-38.

Lerner, J., and P. Tetlock. 1999. Accounting for the effects of accountability. Psychological Bulletin 125(2): 255275.

Libby, R., R. Bloomfield, and M. Nelson. 2002. Experimental research in financial accounting. Accounting, Organizations, and Society 27(8): 775-810.

Magee, R., and M. Tseng. 1990. Audit pricing and independence. The Accounting Review 65(2): 315-336.

Mazar, N., O. Amir, and D. Ariely. 2008. The dishonesty of honest people: A theory of self-concept maintenance. Journal of Marketing Research 45: 633-644.

Murphy, K. 1993. Honesty in the Workplace. Pacific Grove, CA: Brooks/Cole.

PricewaterhouseCoopers, LLP. 2009. Comment Letter \#014 to PCAOB Rulemaking Docket Matter No. 29. http://pcaobus.org/Rules/Rulemaking/Docket029/014_PwC.pdf.

Public Company Accounting Oversight Board (PCAOB). 2008. Standing Advisory Group Meeting. Panel Discussion - Signing the Auditor's Report. (October 22-23). Washington, D. C.: PCAOB. . 2009. Concept Release on Requiring the Engagement Partner to Sign the Audit Report. PCAOB Release No. 2009-005. (July 28). Washington, D. C.: PCAOB. . 2015. Improving the Transparency of Audits: Rules to Require Disclosure of Certain Audit Participants on a New PCAOB Form and Related Amendments to Auditing Standards. PCAOB Release No. 2015-008. Washington, D. C.: PCAOB.

Schatzberg, J., G. Sevcik, B. Shapiro, L. Thorne, and R. Wallace, R. 2005. A reexamination of behavior in experimental audit markets: The effects of moral reasoning and economic incentives on auditor reporting and fees. Contemporary Accounting Research 22(1): 229-264.

Stevens, D. 2002. The effects of reputation and ethics on budgetary slack. Journal of Management Accounting Research 14: 153-171. . 2019. Social Norms and the Theory of the Firm: A Foundational Approach. Cambridge, UK: Cambridge University Press.

Tan, C., C. Jubb, and K. Houghton. 1997. Auditor judgments: The effects of the partner's views on decision outcomes and cognitive effort. Behavioral Research in Accounting 9: 157-175.

U.S. Department of the Treasury. 2008. Final Report of the Advisory Committee on the Auditing Profession to the U.S. Department of the Treasury (October 6): VII:19-VII:20; http://www.treas.gov/offices/domesticfinance/acap/docs/final-report.pdf.

Wilks, T. 2002. Predecisional distortion of evidence as a consequence of real-time audit review. The Accounting Review 77(1): 51-71. 
This is an author-produced, peer-reviewed version of this article. The final, definitive version of this document can be found online at Journal of Business Ethics, published by Springer Nature. Copyright restrictions may apply. doi: 10.1007/s10551-017-3561-z

TABLE 1

\section{Experimental Payouts by Participant-type}

\begin{tabular}{|c|c|c|c|}
\hline Participant-Type & Mean & Minimum & Maximum \\
\hline Auditors (Verifiers) & $\$ 25.83$ & $\$ 10.00$ & $\$ 39.25$ \\
\hline Clients (Sellers) & $\$ 35.65$ & $\$ 24.38$ & $\$ 51.84$ \\
\hline Investors (Buyers) & $\$ 20.17$ & $\$ 11.00$ & $\$ 27.00$ \\
\hline \multicolumn{4}{|c|}{$\begin{array}{l}\text { All participants were paid a } \$ 10 \text { show-up fee in addition to their cumulative earnings during the } \\
\text { experimental session. Auditors began the experiment with an initial endowment of } \$ 10 \text { and received their } \\
\text { selected audit fee less a fixed observation cost of } \$ 1.60 \text {, less an initial learning cost of } \$ 0.40 \text {, and less a } \\
\$ 0.05 \text { misreporting fee each time the auditor reported the value of the asset as high ( } \$ 3.68 \text { ). Auditors } \\
\text { could avoid the initial learning fee if they were rehired by the same client in period two of a given trading } \\
\text { year. Auditors also received } \$ 0.20 \text { per period to reduce differences in payouts among participants. Clients } \\
\text { began the experiment with an initial endowment of } \$ 10 \text { and received the auditor reported value of their } \\
\text { asset each period (either } \$ 2.68 \text { or } \$ 3.68 \text { ) less the selected audit fee and less a } \$ 0.30 \text { new hire fee. Clients } \\
\text { could avoid the new hire fee in period two of a given trading year by selecting the incumbent auditor. } \\
\text { Investors began the experiment with an initial endowment of } \$ 20 \text { and made } \$ 0.00 \text { each time their auditor } \\
\text { truthfully reported the value of the asset as low ( } \$ 2.68) \text { and lost } \$ 1.00 \text { each time their auditor misreported } \\
\text { the value of the asset as high }(\$ 3.68) \text {. }\end{array}$} \\
\hline
\end{tabular}


This is an author-produced, peer-reviewed version of this article. The final, definitive version of this document can be found online at Journal of Business Ethics, published by Springer Nature. Copyright restrictions may apply. doi: 10.1007/s10551-017-3561-z

TABLE 2

Experimental Design and Social Norm Sensitivity Measures

Panel A: Full Experimental Design

\begin{tabular}{|l|c|c|c|}
\cline { 2 - 4 } \multicolumn{1}{c|}{} & \multicolumn{2}{c|}{ Experimental Conditions } \\
\hline Number of Sessions & $\begin{array}{c}\text { No Disclosure or } \\
\text { Signature }\end{array}$ & Disclosure Only & $\begin{array}{c}\text { Disclosure and } \\
\text { Signature }\end{array}$ \\
Total Participants & 2 sessions & 2 sessions & 2 sessions \\
Auditor Participants & 40 & 40 & 40 \\
Total Trading Years & 16 & 16 & 16 \\
Periods per Trading Year & 10 & 10 & 2 \\
Reporting Observations & 2 & 2 & 320 \\
\hline
\end{tabular}

Panel B: Social Norm Sensitivity Measures for Auditor Participants in Period One

\begin{tabular}{|l|c|c|c|c|c|c|c|c|c|}
\cline { 2 - 12 } \multicolumn{1}{c|}{} & \multicolumn{9}{c|}{ Experimental Conditions } \\
\cline { 2 - 12 } \multicolumn{1}{c|}{} & \multicolumn{3}{c|}{$\begin{array}{c}\text { No Disclosure or } \\
\text { Signature }\end{array}$} & \multicolumn{3}{c|}{ Disclosure Only } & \multicolumn{4}{c|}{$\begin{array}{c}\text { Disclosure and } \\
\text { Signature }\end{array}$} \\
\hline Traditional Values & 160 & 10.23 & 3.162 & 142 & 9.18 & 3.205 & 134 & 8.44 & 2.976 \\
\hline Low Traditional Values & 52 & 5.33 & 2.881 & 105 & 8.02 & 1.152 & 52 & 7.04 & 1.546 \\
High Traditional Values & 108 & 10.75 & 1.601 & 37 & 12.03 & 2.101 & 82 & 11.84 & 1.959 \\
\hline Responsibility & 160 & 12.88 & 2.820 & 142 & 11.95 & 3.042 & 134 & 10.73 & 2.517 \\
\hline Low Responsibility & 133 & 10.20 & 2.138 & 52 & 8.37 & 1.657 & 70 & 10.34 & 1.339 \\
High Responsibility & 27 & 15.81 & 1.210 & 90 & 15.02 & 1.038 & 64 & 14.19 & 0.833 \\
\hline
\end{tabular}

Panel A presents our full experimental design. Two sessions were conducted for each experimental condition via networked computer terminals using Z-tree software (Fischbacher, 2007). In the No Disclosure or Signature experimental control condition, the auditor made reporting decisions without either an identity disclosure or a signature requirement. In the Disclosure Only experimental condition the auditor's name was disclosed to the investor as part of the audit report. In the Disclosure and Signature experimental condition the auditor's name was disclosed to the investor and the auditor also typed their name as part of the audit report. Each session was conducted with enough participants to allow two markets to operate simultaneously. Each market consisted of four auditors, four clients, and two investors. Each trading year consisted of two periods, whereby auditors and clients could reduce costs in period two by recontracting (See Table 1). To eliminate group confounds and learning effects, participants were randomly reassigned to new market groups at the end of each trading year.

Panel B reports a summary of our social norm sensitivity measures in period one. As with prior experimental audit markets, we focus on period one where auditor participants have an incentive to misreport in the audit report. The Traditional Values scale of the JPI-R questionnaire measures the degree to which an individual incorporates old values such as honesty, frugality, modesty, respect for authority, and patriotism, and ranges from 0 to 20 . High Traditional Values incorporates participants who score above the sample median for this scale. The Responsibility scale of the JPI-R measures a person's overall sensitivity to moral obligations to other people and to society at large, and ranges from 0 to 20. High Responsibility incorporates participants who score above the sample median for this scale. The imbalance in cell sizes for the social norm measures is due to the fact that each auditor could be selected by up to four clients. Further, some auditor participants were removed from the analyses because they went bankrupt (cumulative earnings were negative) during the experimental session. However, the results reported herein are qualitatively and inferentially similar if all auditor participants are included in the analysis. 
This is an author-produced, peer-reviewed version of this article. The final, definitive version of this document can be found online at Journal of Business Ethics, published by Springer Nature. Copyright restrictions may apply. doi: 10.1007/s10551-017-3561-z

TABLE 3

\section{Misreporting in Period One across Experimental Conditions and} by Low and High Social Norm Sensitivity ${ }^{\dagger}$

\begin{tabular}{|c|c|c|c|c|c|c|c|c|c|}
\hline & \multicolumn{9}{|c|}{ Experimental Conditions } \\
\hline & \multicolumn{3}{|c|}{$\begin{array}{l}\text { No Disclosure or } \\
\text { Signature }\end{array}$} & \multicolumn{3}{|c|}{ Disclosure Only } & \multicolumn{3}{|c|}{$\begin{array}{l}\text { Disclosure and } \\
\text { Signature }\end{array}$} \\
\hline & $\mathbf{n}$ & Mean & Std. Dev. & $\mathbf{n}$ & Mean & Std. Dev. & $\mathbf{n}$ & Mean & Std. Dev. \\
\hline Overall Misreporting & 160 & $41.9 \%$ & 0.495 & 142 & $30.3 \%$ & 0.461 & 134 & $26.1 \%$ & 0.441 \\
\hline Low Traditional Values & 52 & $67.3 \%$ & 0.474 & 105 & $31.4 \%$ & 0.466 & 52 & $32.7 \%$ & 0.474 \\
\hline High Traditional Values & 108 & $29.6 \%$ & 0.459 & 37 & $27.0 \%$ & 0.450 & 82 & $22.0 \%$ & 0.416 \\
\hline Low Responsibility & 133 & $42.1 \%$ & 0.496 & 52 & $51.9 \%$ & 0.505 & 70 & $47.1 \%$ & 0.503 \\
\hline High Responsibility & 27 & $40.7 \%$ & 0.501 & 90 & $17.8 \%$ & 0.384 & 64 & $3.1 \%$ & 0.175 \\
\hline
\end{tabular}

${ }^{\dagger}$ Misreporting is a dichotomous variable coded 1 if the auditor misreported in period one and 0 otherwise. As with prior experimental audit markets, we focus on period one where auditor participants have an incentive to misreport in the audit report. The Traditional Values scale of the JPI-R questionnaire measures the degree to which an individual incorporates old values such as honesty, frugality, modesty, respect for authority, and patriotism, and ranges from 0 to 20. High Traditional Values incorporates participants who score above the sample median for this scale. The Responsibility scale of the JPI-R measures a person's overall sensitivity to moral obligations to other people and to society at large, and ranges from 0 to 20. High Responsibility incorporates participants who score above the sample median for this scale. 
This is an author-produced, peer-reviewed version of this article. The final, definitive version of this document can be found online at Journal of Business Ethics, published by Springer Nature. Copyright restrictions may apply. doi: 10.1007/s10551-017-3561-z

\section{TABLE 4}

\section{Logistic Regression Models of Misreporting in Period One}

\begin{tabular}{|c|c|c|c|c|c|}
\hline \multicolumn{6}{|c|}{ Model 1: Misreport $^{\dagger}=\alpha_{0}+\beta_{1}$ Disclosure $+\beta_{2}$ Signature $\&$ Disclosure $+\varepsilon$} \\
\hline \multicolumn{6}{|c|}{ Model 2: Misreport ${ }^{\dagger}=\alpha_{0}+\beta_{1}$ Disclosure $+\beta_{2}$ Signature \& Disclosure $+\beta_{3}$ Fee $+\varepsilon$} \\
\hline \multicolumn{6}{|c|}{$\begin{array}{c}\text { Model 3: } \text { Misreport }{ }^{\dagger}=\alpha_{0}+\beta_{1} \text { Disclosure }+\beta_{2} \text { Signature } \& \text { Disclosure }+\beta_{3} \text { Fee }+\beta_{4} \text { Responsibility }+\beta_{5} \text { Traditional } \\
\text { Values }+\varepsilon\end{array}$} \\
\hline \multicolumn{6}{|c|}{$\begin{array}{c}\text { Model 4: } \text { Misreport }{ }^{\dagger}=\alpha_{0}+\beta_{1} \text { Disclosure }+\beta_{2} \text { Signature \& Disclosure }+\beta_{3} \text { Fee }+\beta_{4} \text { Responsibility }+\beta_{5} \text { Traditional } \\
\text { Values }+\beta_{6} \text { HIR }+\beta_{7} \text { HIRxDO }+\beta_{8} \text { HIRxDS }+\varepsilon\end{array}$} \\
\hline Predicte & ign & Model 1 & Model 2 & Model 3 & Model 4 \\
\hline Intercept & & $\begin{array}{c}-\mathbf{0 . 7 1 6} * * * \\
(.103) \\
\mathrm{p}<.001\end{array}$ & $\begin{array}{c}\mathbf{0 . 7 2 3 * * *} \\
(.104) \\
\mathrm{p}<.001\end{array}$ & $\begin{array}{c}\mathbf{0 . 7 9 6 * * *} \\
(.112) \\
p<.001\end{array}$ & $\begin{array}{c}-0.794 * * * \\
(.141) \\
p<.001\end{array}$ \\
\hline Disclosure (DO) ${ }^{a}$ & - & $\begin{array}{c}-\mathbf{0 . 5 0 6} * * \\
(.243) \\
p=.019\end{array}$ & $\begin{array}{r}-\mathbf{0 . 4 5 2 * *} \\
(.245) \\
\mathrm{p}=.033\end{array}$ & $\begin{array}{c}-\mathbf{0 . 2 0 1} \\
\quad(.266) \\
p=.225\end{array}$ & $\begin{array}{r}-\mathbf{0 . 2 0 0} \\
(.280) \\
p=.122\end{array}$ \\
\hline Disclosure \& Signature (DS) ${ }^{b}$ & - & $\begin{array}{c}-\mathbf{0 . 7 1 2} * * * \\
(.254) \\
\mathrm{p}=.003\end{array}$ & $\begin{array}{c}-\mathbf{0 . 5 9 7 * *} \\
(.260) \\
\mathrm{p}=.011\end{array}$ & $\begin{array}{c}-\mathbf{0 . 3 9 3 *} \\
\quad(.271) \\
\mathrm{p}=.074\end{array}$ & $\begin{array}{c}-1.039 * * * \\
(.387) \\
p=.004\end{array}$ \\
\hline Fee $^{c}$ & + & & $\begin{array}{c}\text { 0.006** } \\
\quad(.003) \\
p=.018\end{array}$ & $\begin{array}{c}\mathbf{0 . 0 0 5} * * \\
(.003) \\
p=.038\end{array}$ & $\begin{array}{c}\mathbf{0 . 0 0 6 * *} \\
(.003) \\
p=.035\end{array}$ \\
\hline Responsibility (RES) ${ }^{d}$ & - & & & $\begin{array}{c}-\mathbf{0 . 2 4 8 * * *} \\
(.045) \\
\mathrm{p}<.001\end{array}$ & \\
\hline Traditional Values (TV) ${ }^{e}$ & - & & & $\begin{array}{c}-\mathbf{0 . 0 0 3} \\
\quad(.047) \\
\mathrm{p}=.477\end{array}$ & \\
\hline High Responsibility (HIR) ${ }^{\mathrm{f}}$ & - & & & & $\begin{array}{c}-\mathbf{1 . 5 7 4 * * *} \\
(.309) \\
p<.001\end{array}$ \\
\hline HIRxDO & - & & & & $\begin{array}{c}-1.478^{* * *} \\
(.584) \\
p=.006\end{array}$ \\
\hline HIRxDS & - & & & & $\begin{array}{c}-3.200 * * * \\
(.863) \\
p<.001\end{array}$ \\
\hline \multicolumn{6}{|l|}{ Model Statistics } \\
\hline Chi-square & & 8.943 & 13.466 & 58.853 & 69.575 \\
\hline $\mathbf{N}$ & & 436 & 436 & 436 & 436 \\
\hline Model df & & 2 & 3 & 5 & 7 \\
\hline Overall Model Significance & & .011 & .004 & $\mathrm{p}<.001$ & $\mathrm{p}<.001$ \\
\hline Nagelkerke $R^{2}$ & & .028 & .042 & .175 & .205 \\
\hline
\end{tabular}

Table 4 presents the results of logistic regression models of misreporting in the audit report in period one. Standard errors for each regression coefficient are reported in parentheses. ${ }^{* * *}, * *, *$ Denote one-tailed significance at the $.01, .05$, and .10 levels respectively.

+ Misreport: Dichotomous variable coded as 1 if auditor misreported in period one and 0 otherwise.

a Disclosure (DO): Coded as 1 if auditors' names were disclosed to the investors and 0 otherwise.

b Disclosure and Signature (DS): Coded as 1 if auditors' typed in their name as part of the audit and their names were disclosed to investors and 0 otherwise.

c Fee: Accepted audit fee bid.

d Responsibility (RES): Overall sensitivity to moral obligations to other people and to society at large as measured by the Responsibility scale of the JPI-R, which ranges from 0 to 20.

$e$ Traditional Values (TV): The degree to which an individual incorporates old values, such as honesty, frugality, modesty, respect for authority, and patriotism as measured by the Traditional Values scale of the JPI-R, which ranges from 0 to 20 .

$f$ HIR: High Responsibility is a dichotomous variable coded as 1 if the participant's Responsibility score was above the median and 0 otherwise. 